\title{
Undercut tolerances in industry from a fracture mechanic perspective
}

\author{
Ceferino Steimbreger ${ }^{1, *}$, and Mirco Chapetti ${ }^{1}$ \\ ${ }^{1}$ Laboratory of Experimental Mechanics (LABMEX), INTEMA (Institute for Material Science and Technology), CONICET - University \\ of Mar del Plata, J.B. Justo 4302, (B7608FDQ), Mar del Plata, Argentina.
}

\begin{abstract}
Fatigue is an important damage mechanism that particularly affects welded components, since they are likely to present residual stresses, inhomogeneities and stress raisers. Assessment of cyclic load effects on welds has concerned both industries and scientist for decades; unexpected failure must be prevented and at the same time, structures must withstand design loads with minimum requirements of material. All these facts together with economic issues have lead to the creation of normative that rule designing and construction of welded components. Particularly, toe undercuts are generally found in large structures, and large scatter and disagreement exists towards their significance and effects. Documents usually limit only their depth without considering radius, width or length, and there is currently no explanation to that fact. Understanding the damaging process will also help to set less conservative tolerances, with consequent cost reduction due to less demanding inspection. The present paper deals with a fracture mechanic approach that uses the Resistance Curve concept to predict fatigue limit of welded components with undercuts. Results revealed that depth is the most influencing variable, and it can be used as the limiting parameter in design regulations. Moreover, good correlation was obtained with FAT values normally assigned to this kind of defect.
\end{abstract}

\section{Introduction}

Tolerances for weld defects have been established in many codes of construction, in order to keep failure risk to a minimum. Initially, some of these documents were intended as means of communication between the welder and the engineer and they were based mainly on good workmanship and experience. Nowadays, their scope is much more important and their usage is widespread all over the world. Furthermore, some standards have recently included weld defect evaluation under cyclic loading, evincing the increasing interest of parties in achieving safe structures.

In spite of all these developments in the field of welded constructions, lack of agreement between codes and standards with respect to tolerances is evident. Moreover, limits are sometimes over-conservative and hard to measure for the unaided eye, which considerably delays inspection process. Therefore, an evaluation of tolerances with a scientific basis is needed.

In general, acceptance levels for weld defects are determined by considering quality control levels or weld quality systems, such as those in ISO 5817 [1]. They allow the existence of flaws in a component, provided that their size is less severe than certain limits. In cases where fatigue is an important damaging mechanism, welds are classified into pre-defined details associated to a specific $\mathrm{S}-\mathrm{N}$ curve that defines its safe cyclic behaviour. Although this proved to work well in a variety of situations, no consistent relation can be established between tolerances for defects and the actual damaging phenomenon, which constitutes the main drawback of weld quality systems.

If a flaw in a weld is found to be out of the limits provided by the quality system, immediate rejection can be delayed until a deeper analysis confirms the risk of maintaining that defect in service. In this regard, fitnessfor-purpose/service (FFP/FFS) analyses are normally employed [2-4]. These methods determine in a rational manner, whether a structure or component containing flaws is able to continue in service safely.

In parallel with development of fitness-for-purpose guidelines, fracture mechanic proved to be a powerful tool to determine severity of a variety of discontinuities, and remaining fatigue life of structures. Pertinent documents have included guidelines on fracture mechanics, although some parameters, like threshold stress intensity factor, are usually disregarded or adopt very conservative values [2-6].

Previous works from the authors employed a fracture mechanic methodology based on the resistance curve concept, to determine fatigue strength of welded joints containing undercuts [7]. Results are summarised in Figure 1, in the form of Frost diagram. It was suggested that this methodology may serve as a tool to predict safe acceptance limits to undercuts and other defects.

Corresponding author: cefesteim@gmail.com 


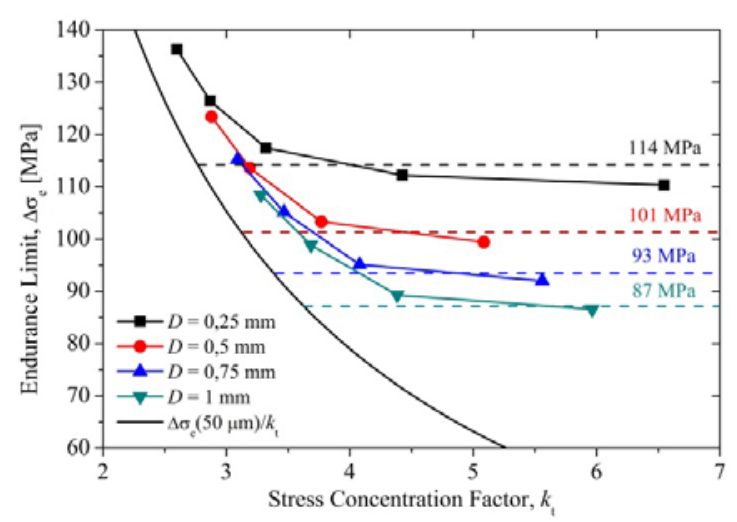

Fig. 1. Frost diagram for a reference plain fatigue limit of $\Delta \sigma_{\mathrm{e}}$ $=315 \mathrm{MPa}\left(a_{\mathrm{i}}=50 \mu \mathrm{m}\right)[7]$.

In order to compare these outcomes with current regulation in the subject, a brief description of relevant normative is carried out in the following paragraphs.

\subsection{AWS D1.1 [8]}

Acceptance criteria for WPS Qualification, and also for Welder and Welding Operator Qualification, limit undercut depth to $1 / 32$ " (1 mm) when performing visual inspection or macroetch tests. Additionally, all welds must meet specified visual acceptance criteria that, in the case of non-tubular connections, depend on whether the structure is statically or cyclically loaded. Under the last mode, undercut depth is limited to $0.25 \mathrm{~mm}$ in primary members under any design loading condition, when the weld is transverse to tensile stress.

\subsection{ASME BPVC [9-11]}

As a result of static strength considerations, undercuts whose depth is beyond a minimum section thickness are forbidden. In the case of finished longitudinal and circumferential joints in boilers [9], depth must not exceed $0.8 \mathrm{~mm}$, or $10 \%$ of the wall thickness, whichever is less. Moreover, a smooth transition between the surfaces being joined is required. Defects found to be rejectable must be removed, rewelded and re-examined.

An important fact in the ASME BPVC is that tolerances for undercut depth are similar in all sections. However, some differences can be found in relation to thickness dependence and undercut length. For example, Subsection NF in Section III [10] presents less stringent acceptance limits for shorter undercuts (smaller length) or thicker members. Both variations rely on static strength considerations and on reduction of required section thickness. This situation is held throughout the code and although some sections do include fatigue considerations, no clear relation between undercut tolerances and cyclic loading can be established. It is worth mentioning, that measurement of reduction in thickness due to undercutting, is not required if there is no disagreement between the involved parties about its acceptability [11].
If fracture mechanic analyses or refined fatigue assessment are necessary, API 579-1/ASME FFS-1 [3] is referred throughout the code.

\subsection{SS-EN ISO 5817 [1]}

Quality levels are designated by letters B, C and D, with the former corresponding to the highest requirements on the final weld. These groups are based on production and good workmanship.

Limits proposed in this document are directly applicable to visual testing of weldments. In the case of welds with thickness over $3 \mathrm{~mm}$, quality level B limits undercut depth to $D \leq 0.05 t$ but max. $0.5 \mathrm{~mm}$; level C to $D \leq 0.1 t$ but max. $0.5 \mathrm{~mm}$; and level $\mathrm{D}$ accepts undercuts with $D \leq 0.2 t$ but max. $1 \mathrm{~mm}$.

If loading mode is cyclic, then quality levels must additionally meet fatigue requirements in terms of fatigue classes (FAT). FAT value refers to the stress range at $2.10^{6}$ cycles for a two-sided survival probability of $95 \%$, based on mean curves proposed by IIW Recommendations [5]. The basis of these additional requirements is that limits for imperfections in quality level $\mathrm{C}$ and $\mathrm{B}$ must be adjusted in order to compliment fatigue class FAT 63 and FAT 90, respectively. Supplementary fatigue level FAT 125 can be assigned to weld quality B, for some imperfections, although this is not generally achieved in the as-welded condition. Static limits for undercuts satisfy fatigue requirements for levels C63 and B90. However, B 125 demands removal of this type of imperfection.

It can also be highlighted, that a smooth transition is required, in order to achieve good-workmanship standards. This restricts the application of the document to solely blunted undercuts (i.e. not too sharp).

\subsection{BS 7608 [12]}

Quality control can sometimes be assessed by considering the same acceptance criteria in production as those adopted for procedure or weld qualification $[8,13]$ or in BS EN ISO 5817 [1]. Such provisions rely on arbitrary quality criteria and they may not be suitable for higher fatigue class needs. Moreover, their requirements are likely to incur additional cost for lower fatigue classes. Therefore, a fitness-for-purpose assessment is generally preferred to specify quality requirements.

Tolerance for undercuts at the toe of welds subjected to cyclic loading can also be determined based on fatigue test results, particularly those obtained by Petershagen [14]. Undercuts will therefore have an associated S-N curve, depending on its depth/thickness ratio. Acceptance or rejection of the flaw is decided by comparing this actual quality category with the required quality category. The latter can be determined with the required stress range and design fatigue life, or alternatively with the weld quality category of the reference detail (e.g. butt joint). Requirements for undercuts are shown in Table 1. Correspondence with BS 7910 quality categories [2] is also displayed. 
Table 1. Fatigue based tolerances for undercuts in transversely stressed butt-welds $[2,12]$.

\begin{tabular}{|l|l|l|}
\hline Required class & Equivalent BS 7910 & Undercut depth, $D$ \\
\cline { 3 - 3 } (FAT) & quality category & Butt welds \\
\hline C & - & Not permitted \\
\hline D & Q1 & $0.025 t, \leq 1 \mathrm{~mm}$ \\
\hline E & Q2 & $0.05 t, \leq 1 \mathrm{~mm}$ \\
\hline F & Q3 & $0.075 t, \leq 1 \mathrm{~mm}$ \\
\hline F2 & Q4 & $0.1 t, \leq 1 \mathrm{~mm}$ \\
\hline G & Q5 & $0.1 t, \leq 1 \mathrm{~mm}$ \\
\hline
\end{tabular}

Some validity boundaries apply to Table 1 . First of all, it is restricted to shallow undercuts at the toe of perfectly aligned joints. In the case of sharp defects, where depth cannot be measured accurately, probability of crack nucleation is higher, and they must therefore be rejected according to this standard. Additionally, plate thickness must be in the range of 10 to $40 \mathrm{~mm}$. Undercuts formed in materials out of this limits should be assessed as planar flaws following BS 7910 procedures [2]. Validity limitations are necessary due to the restricted database available [14]. In cases where stresses act parallel to weld direction, there is no limiting size for undercut depth, since they do not affect fatigue behaviour under this condition.

As it was mentioned earlier, limits shown in Table 1 were deduced from large experimental fatigue data in transversely-stressed butt and fillet steel joints, in which undercuts were either naturally generated or artificially machined at the toe. These results were analysed statistically assuming a log-normal distribution of fatigue life to obtain the lower $95 \%$ confidence limit, corresponding to $97.7 \%$ probability of survival. Quality category was determined by comparing these data with that of flawless welds. Particularly, reduction in fatigue strength due to undercut depth was quantified in terms of steps in the grid of quality category S-N curves. Parameter $\mathrm{D} / \mathrm{t}$ was found to best reduce scatter in experimental data $[14,15]$.

\subsection{API 1104 [16]}

Undercuts must fulfil specific requirements when visual inspecting: their depth at the toe of the final bead on the outside of the pipe shall not exceed $0.8 \mathrm{~mm}$ or $12.5 \%$ of the pipe wall thickness, whichever is smaller. Moreover, there must not be more than $50 \mathrm{~mm}$ of undercutting in any continuous $300 \mathrm{~mm}$ length of weld.

In addition to these requirements, depth of undercuts found in the cover or root bead shall not be larger than values given in Table 2, when inspection is carried out visually or by mechanical means. When employing other non-destructive techniques like radiography, magnetic particles or ultrasonic method, undercuts at the cover pass or root bead must only satisfy length restrictions.

Previous tolerances for undercuts are based on empirical criteria for good workmanship. Although these limits have proven to be reliable in pipeline systems throughout the years, if a more stringent analysis is desired and it is approved by the company, fitness-forpurpose assessment can be used [2].
Table 2. Maximum depth of undercuts, for visual and mechanical inspection [16].

\begin{tabular}{|l|l|}
\hline \multicolumn{1}{|c|}{ Depth } & \multicolumn{1}{c|}{ Length } \\
\hline $\begin{array}{l}D>0.8 \mathrm{~mm} \text { or } D>0.125 \\
t, \text { whichever is smaller }\end{array}$ & Not acceptable \\
\hline $\begin{array}{l}0.4 \mathrm{~mm}<D \leq 0.8 \mathrm{~mm} \text { or } \\
0.06 t<D \leq 0.125 \text { t } t,\end{array}$ & $\begin{array}{l}50 \mathrm{~mm} \text { in a continuous } 300 \mathrm{~mm} \\
\text { weld length or one-sixth the weld } \\
\text { whichever is smaller }\end{array}$ \\
\hline $\begin{array}{l}D \leq 0.4 \mathrm{~mm} \text { or } D \leq 0.06 \\
t, \text { whichever is smaller }\end{array}$ & Acceptable, regardless of length \\
\hline
\end{tabular}

In summary, high cycle fatigue considerations are lightly accounted for in this standard, and it is not clear weather tolerances are defined for static or cyclic loading conditions. In spite of this, limit values adopted throughout the document are useful for comparing with other standards and codes.

\subsection{IIW Recommendations $[5,17]$}

Undercuts are regarded in the guideline as additive imperfection, which means that they are adding their effect on fatigue behaviour (e.g., undercut and toe radius). For rapid assessment of these flaws, Table 3 is given, which is based on experimental tests and results from literature [14, 18]. However, IIW recommends the effective notch stress approach or fracture mechanics for deeper analyses of undercut's effect.

Table 3. Acceptance levels for Weld toe undercuts in steel, according to IIW recommendations [5, 17].

\begin{tabular}{|l|l|l|}
\hline \multirow{2}{*}{$\begin{array}{l}\text { Fatigue class } \\
(\text { FAT })\end{array}$} & \multicolumn{2}{|c|}{ Allowable undercut, $D / t$} \\
\cline { 2 - 3 } & Butt welds & Fillet welds \\
\hline 100 & 0.025 & Not applicable \\
\hline 90 & 0.05 & Not applicable \\
\hline 80 & 0.075 & 0.05 \\
\hline 71 & 0.1 & 0.075 \\
\hline 63 and lower & 0.1 & 0.1 \\
\hline
\end{tabular}

\subsection{VOLVO STD 181-0004 [19]}

VOLVO made the first attempts to include fatigue consideration in old weld quality systems, which were originally based on good workmanship in fabrication [20]. Although, normal workmanship conditions are related to a certain extent to adequate weld performance, a proper analysis based on fitness-for purpose was not established. Particularly, structures subjected to fatigue loading needed special attention. As a result, this standard was developed in 2008, by considering IIW Recommendations [5]. Later, IIW published its own guideline to weld quality systems [17], based on VOLVO standard. In parallel, ISO added fatigue consideration to its latest version in 2014 [1].

Most requirements in STD 181-004 are based on notch-stress analyses. Jonsson et al. [21] proposed acceptance levels for undercuts based on the effective notch stress approach [22] that assigns a radius of $1 \mathrm{~mm}$ to the undercut root. Tolerances were obtained by considering that the worst acceptable defect is given by a stress value two standard deviations above the stress 
level of a normal weld, free from undercuts [21]. This limit, or safe value of the stress, is later compared to the stress at the root of an undercut for different depths. Intersection of the two variables determines the limit for undercut depth.

By applying this procedure to butt and fillet welds, limiting tolerances in terms of $D / t$ were obtained. An average of the two was considered for the weld quality system. Same methodology can be extended to high quality welds. STD 181-004 adopted less stringent requirements for undercut depth in qualities VD and VC. These classes need to satisfy additional demands in terms of the "outer transition radius", which should not be lower than $0.3 \mathrm{~mm}$ and $1 \mathrm{~mm}$, respectively. This condition differs from ISO 5817, that solely request a smooth transition between the weld and the base material.

It is interesting to note, that results are in accordance with IIW recommendations [5, 17], whose acceptance limits are based on Petershagen's work [14]. Both researches are based on stress analysis and no crack consideration is involved.

\subsection{DNVGL RP-C203 [6]}

It is recommended to construct a proper WPS to avoid deep undercuts in production. Common workmanship standards are considered in design S-N curves, and default tolerance for this type of defect is normally limited to $0.6 \mathrm{~mm}$ [23]. However, specific requirements can be assigned depending on the desired fatigue strength. Tolerances for undercuts are then limited to null for S-N curves better than D, $0.5 \mathrm{~mm}$ for classes $\mathrm{F}$ to $\mathrm{D}$, and $1 \mathrm{~mm}$ for class $\mathrm{F} 1$ and lower. In the case of butt welds with desired fatigue behaviour better than class D, ISO level B125 applies (ISO 5817).

\section{Assumptions}

In order to determine stress intensity factors associated to a crack growing from the undercut root, a finite element software [24] was employed. Two-dimensional linear elastic model was considered and symmetry was assumed. Weld geometry is displayed in Figure 2, together with symmetric model. Thickness is $19 \mathrm{~mm}$ and weld with a reinforcement angle is $147^{\circ}$. Load configuration and boundary conditions are also shown. Four point bending was considered. Minor and major span are represented by $s$ and $L$, respectively, $t$ is the plate thickness and $P$ is the applied load. All these variables define the maximum nominal stress on the surface that is used in the calculations.

Analysis carried out in welds with undercuts and its usage for safe tolerance determination in standards, is limited to a $19 \mathrm{~mm}$ stress-relieved weld, made of structural steel (A36) and loaded in four point bending scheme [7]. In order to extend these results to other buttwelds, it should be verified that these outcomes are conservative, or at least similar to those for other materials, thicknesses and loading conditions.

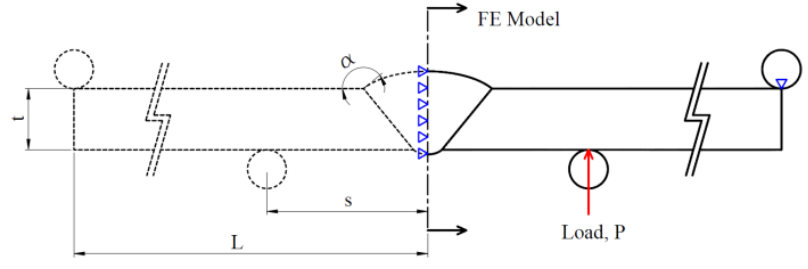

Fig. 2. Geometry, load configuration and boundary conditions of the finite element model. $t$ is the plate thickness, $\alpha$ is the reinforcement angle, $s$ is half the minor span, $L$ is half the major span and $P$ is the applied load.

\section{Results and discussions}

In order to compare acceptance limits for undercut at the toe of welded connections in current regulations, it is important to mention, that the preferred parameter to do this is undercut depth, $D$. It can be found in literature, that this measure provided the best fitting of experimental results. The work of Petershagen [14] revealed that $D / t$ reduced even more the scatter in large amount of data. Some documents demand additional requirements in terms of undercut length $[8,16]$ and weld toe radius [19], and others distinguish between different types of joints and loading directions. Herein, the most dangerous situation for a butt connection is considered, i.e. an undercut along the whole length of the weld bead, loaded transversely.

Figure 3 summarises design fatigue curves, which are relevant for assessing cyclic behaviour in a butt-welded joint. FAT 80, 90 and 100 corresponding to IIW recommendations, present a change in slope to $m=22$ for cycles above $1.10^{7}$. BS 7608 assigns a curve similar to FAT 90, but the knee point in the former case determines the fatigue strength for infinite life and they do not present a slope to account for ultra-high cycle fatigue. Likewise, AWS follow a FAT 90 trend until $4.10^{6}$, where it becomes horizontal.

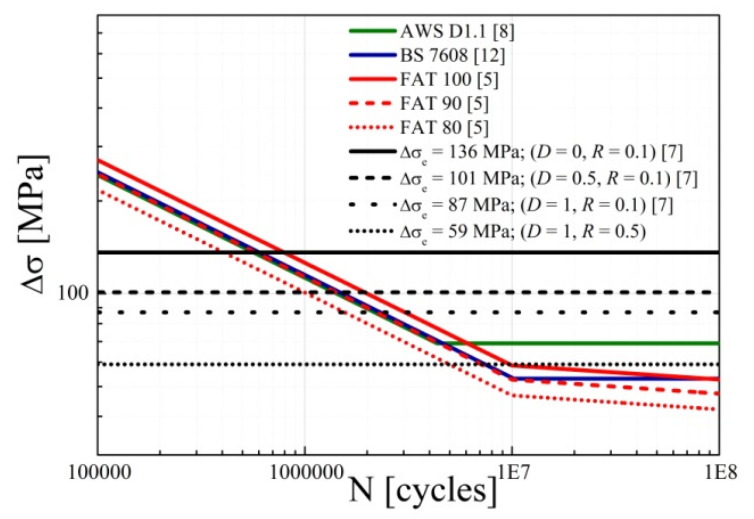

Figure 3: S-N curves employed in different codes and standards, and fatigue limit results from prediction.

In the same plot depicted in Figure 3, 4 horizontal curves are also provided. They correspond to fatigue limits from predictions for a stress-relieved $19 \mathrm{~mm}$ butt weld without undercut (straight line), a stress-relieved 19 $\mathrm{mm}$ butt weld with an undercut $0.5 \mathrm{~mm}$ deep (slashed line), a stress-relieved $19 \mathrm{~mm}$ butt weld with an undercut $1 \mathrm{~mm}$ deep (dotted line) and a butt weld with an 
undercut $1 \mathrm{~mm}$ deep but including residual stresses (short dotted line). The latter was obtained as explained below. Note that the value of fatigue strength at $2.10^{6}$ cycles is similar to predictions for welds with undercuts. On the other hand, fatigue limit in theoretical curves defined as the knee point, are somewhat closer to predictions for a weld with $1 \mathrm{~mm}$ undercut, and considering residual stresses $(R=0.5)$.

Majority of codes and standards that are relevant to fatigue design make use of a reference stress in the design S-N curve for fatigue assessment. Definition of this limit depends on each document, but it is generally related to the FAT value and in some cases to the stress where a change in slope in the $\mathrm{S}-\mathrm{N}$ curve is defined.

Table 4 summarises acceptance limits found in normative, when structures and components withstand cyclic loads. Some documents assign different tolerances to different desired fatigue strength, but others do not consider alternative levels of conservatism [8-11, 16]. As it is expected, codes of construction like AWS and ASME adopt the most conservative values. In the former case, it limited undercut depth to $0.25 \mathrm{~mm}$ for more than 30 years without any strength consideration.

Fatigue class corresponding to each weld designation or quality system, is displayed in column two of Table 4. Additionally, FAT values (strength in MPa at $2.10^{6}$ cycles) are provided, based on design S-N curves from each document. In this regard, it must be mentioned that although IIW reference S-N curves prevail in the majority of documents studied in the present work, not all regulations adopt those profiles, as indicated in Figure 3. Therefore, fatigue limits, considered as the "knee-point" in IIW curves, or the stress value at which infinite fatigue life is obtained in others, are listed in column 4.

Analysis carried out by the authors presented results of fatigue limit for butt-welded joints with different undercut configurations (see Figure 1). This means that infinite fatigue life is obtained in those welds if loaded below that stress. Although comparison of results with fatigue limits (see column 4 of Table 4) is reasonable from a safe-life design point of view, this methodology can be over-conservative in cases where fatigue is not the primary damage mechanism, like in nuclear reactors or oil piping systems. Moreover, even in situations where severe fatigue damage is expected, design is generally based on FAT values, with satisfactory results. Therefore, the use of FAT values is justified and it is valuable to compare tolerances in relevant normative with results from previous work from the authors [7].

Figure 4 illustrates results from Table 4, and shows maximum tolerance for undercut depth, for several desired fatigue strength, in terms of FAT values. It must be highlighted, that connection between points was made by a straight line rather than a stepped profile, as can be found in relevant literature [14]. This was preferred since in real structures a continuous decrease in fatigue strength for increasing undercut depths is expected.
Table 4: Undercut tolerances in codes and standards, for a butt-welded joint, $19 \mathrm{~mm}$ thick.

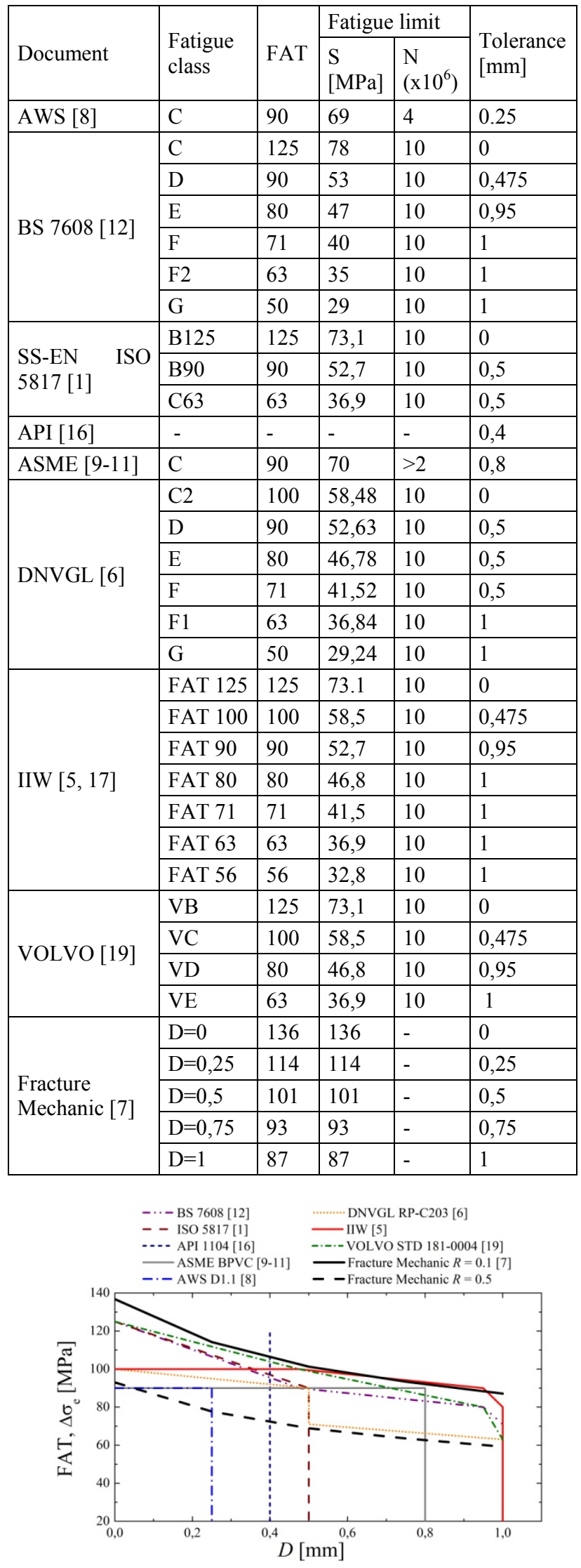

Figure 4: Results from predictions and comparison with regulations. Butt joint, $\mathrm{t}=19 \mathrm{~mm}$, FAT values. 
It can be seen in Figure 4 that AWS D1.1 contains the most conservative tolerances, since no undercuts deeper than $0.25 \mathrm{~mm}$ are permitted. BS 7608, VOLVO STD 181-004 and IIW recommendations suggest similar tendencies, limiting maximum tolerable undercut to 1 mm. ISO 5817 follows a similar trend as VOLVO and $\mathrm{BS}$, up to $0.5 \mathrm{~mm}$, which is the maximum admissible undercut depth in a $19 \mathrm{~mm}$ thick butt-joint. On the contrary, DNVGL RP-C203 shows more conservative strength beyond $D=0.5 \mathrm{~mm}$, but also accepts a maximum permissible depth of $1 \mathrm{~mm}$.

In the same plot, results from author's predictions are displayed with a black straight line. This curve gives the fatigue limit of the weld $(136 \mathrm{MPa})$, when $D=0$, and decreases continuously with undercut depth. Note that it slightly differs from regulations, and it accurately describes the trend followed by most regulations. However, it must be mentioned that predictions developed in this work were calculated for a stress ratio $R=0.1$ and they do not account for residual stresses. Normally, design S-N curves are based on extensive experimental data in real welds, and hence they include residual stresses in their definition, as it was pointed out in the introduction.

\subsection{Residual stress correction}

In order to unify criteria in Figure 4 and consider welds containing residual stresses, the change in the resistance curve for different values of stress ratio, $R$ was analysed. As an example, a semi-circular undercut with $D=0.5$ $\mathrm{mm}$ was used. Resistance curve and critical condition in A36 steel is shown with black lines in Figure 5.

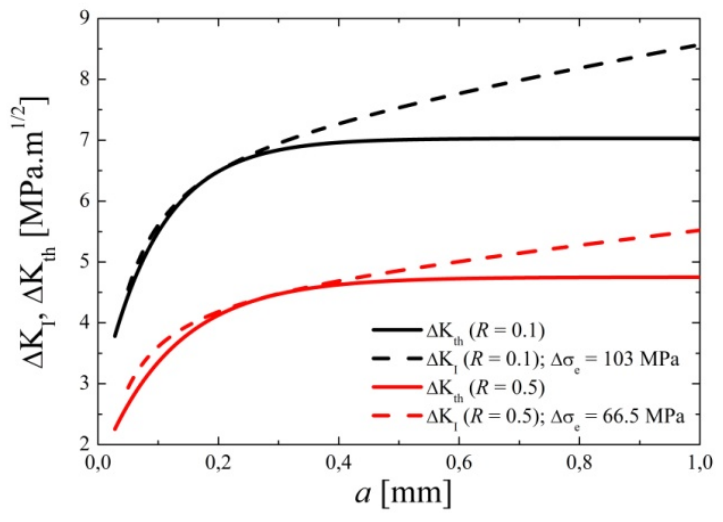

Figure 5: Variation of resistance curve and critical applied stress intensity factor in A36 weld with undercuts $0.5 \mathrm{~mm}$ deep, at different values of $\mathrm{R}$.

In order to assess the effect of residual stresses, dependence of long crack propagation threshold with stress ratio must be known. It was found [25] that the following relation applies to A36 steel:

$$
\Delta K_{\text {thR }}=7.6-5.7 R
$$

A quick examination of Eq. (1) and Figure 5 reveals that plateau given by long crack propagation threshold, is shifted to lower values of $\Delta \mathrm{K}$, when $R$ is increased. Therefore, a reduction in fatigue strength is likewise expected. However, a deeper analysis must consider the change of the plane fatigue limit, $\Delta \sigma_{e R}$, with $R$, which in consequence produces a variation of the microstructural fatigue threshold, $\Delta \mathrm{K}_{\mathrm{dR}}$, according to Eq. (2).

$$
\Delta K_{d R}=Y \Delta \sigma_{e R}(\pi d)^{1 / 2}
$$

where $d$ is value of the strongest microstructural barrier, which is usually determined by ferrite grain size and bainite or martensite lath length [26].

A conservative estimation of the fatigue limit for different values of $R$ can be obtained by means of Goodman's relation. It is easy to demonstrate that Eq. (3) relates stress amplitude for $R=-1, \sigma_{\mathrm{e}-1}$, with stress amplitude at a desired asymmetric stress ratio, $R, \sigma_{\mathrm{AeR}}$.

$$
\sigma_{A e R}=1 /\left\{\left(1 / \sigma_{e-1}\right)+(1+R) /\left[\sigma_{U T S}(1-R)\right]\right\}
$$

where $\sigma_{\text {UTS }}$ is the ultimate tensile strength of the base material (472 MPa for A36).

Since the value of $\Delta \sigma_{\mathrm{eR}}=360 \mathrm{MPa}$ used in predictions corresponds to $R=0.1$, then the inverse procedure should be followed to find $\sigma_{\mathrm{e}-1}$. By doing so, it can be obtained that $\sigma_{\mathrm{e}-1}=337 \mathrm{MPa}$. After this, stress amplitude for other stress ratios can be deducted directly from Eq. (3). Particularly, for $R=0.5, \sigma_{\mathrm{AeR}}=107 \mathrm{MPa}$, and therefore $\Delta \sigma_{\mathrm{AeR}}=214 \mathrm{MPa}$. Finally, by recalling Eq. (2), $\Delta \mathrm{K}_{\mathrm{dR}}=2.25 \mathrm{MPa} \sqrt{\mathrm{m}}$ is obtained. Resistance curves for $R=0.1$ and $R=0.5$ are depicted in Figure 5. It is also indicated in this plot, the curve for the applied stress intensity factor range in the limiting condition (i.e. where it touches the threshold curve in a single point) for $R=$ 0.1 (black dotted line) and an increased stress ratio $R=$ 0.5 (red dotted line). Fatigue strengths resulting in both cases are 103 and $66.5 \mathrm{MPa}$, respectively. This shift is equivalent to a decrease around $35 \%$, which means that a limit load (or equivalently, a limit stress or fatigue limit) $35 \%$ smaller than that for $R=0.1$ could be allowed. These results are displayed with a black broken line in Figure 4, and a clear lower bound to tolerances in industry can be seen.

At the same time, relationship in Eq. (1), gives a value of $7.03 \mathrm{MPa} \sqrt{\mathrm{m}}$ when $R=0.1$ and $4.75 \mathrm{MPa} \sqrt{\mathrm{m}}$ when $R=0.5$. Then, a reduction in $\Delta \mathrm{K}_{\mathrm{thR}}$ around $32 \%$ is deduced. It must be highlighted that both quantities (that obtained by the resistance curve method and the one calculated directly with Eq. (1)) are similar. Therefore, it can be said that the stress corresponding to the contact point between applied driving force and threshold, is reduced in approximately the same amount as long crack propagation threshold, for two different values of $R$. Therefore, control of this property is relevant when assessing the effect of residual stresses.

\subsection{Thickness correction}

Since the 70 's, it has been known that fatigue strength increases with decreasing thickness. A potential relation was found to best fit experimental results, with the following equation $[27,28]$ :

$$
\sigma_{t} / \sigma^{t R}=\left(t_{R} / t\right)^{n}
$$

Where $\sigma_{\mathrm{tR}}$ is the fatigue limit for a weld on a plate with a reference thickness $t_{R}$, and $\sigma_{\mathrm{t}}$ is the fatigue limit at 
another thickness $t . n$ is the exponent that was found to be close to 0.25 .

Right term in Eq. (4) is defined as the thickness correction/reduction factor in codes and standards. It should be multiplied by the FAT value in order to consider thickness effect in design $[5,6,12]$. This is only done for $t>t_{\mathrm{R}}$, since the benefit of an enhanced fatigue limit for smaller thicknesses is usually disregarded in standards and recommendations.

IIW Recommendations [5] specifies a reference thickness of $t_{\mathrm{R}}=25 \mathrm{~mm}$ and a value of $n$ that depends on the type of joint to be assessed. In the case of transverse as-welded butt joints, $n=0.2$ corresponds. Value of the reference thickness to be used in Eq. (4) is still at open debate. But in general, $t_{\mathrm{R}}=25 \mathrm{~mm}$ and $n=0.2$ is employed in design documents $[5,6,12]$.

On the other hand, resistance curve concept has proved to properly describe changes in fatigue limit due to thickness variations [25]. Additionally, due to the fact that the model employed to determine stress intensity factor is linear elastic, the effect of thickness can be assessed using the same configuration used for $t=19$ $\mathrm{mm}$. By similarity principles, geometry and load scheme can be scaled down in order to have geometrically similar stress distribution and the same nominal stress, but for a different thickness. Many authors [29-31] made use of this method to derive fracture mechanic results from a reference configuration to another.

In the presence of undercuts, scaling down geometry in Figure 2 can be accomplished by considering a constant ratio $D / t$, or keeping undercut depth and shape constant with varying $t$. Results from both situations are shown in Figure 6. Also depicted in this chart is the theoretical relation in Eq. (4), considering $t_{\mathrm{R}}=25 \mathrm{~mm}$ and $n=0.2$. It must be highlighted that results corresponding to semi-circular undercuts correspond well with this theoretical curve.

On the other hand, when analysing data for $D / t=$ $0.5 / 19=$ constant it can be seen a sharp change in slop around $22 \mathrm{~mm}$, associated to a shift in the nonpropagating crack length. The latter presents a sharp step at $t=22 \mathrm{~mm}$, above which $a_{\mathrm{np}}=a_{\mathrm{i}}=0.05 \mathrm{~mm}$, in correspondence with Figure 6.

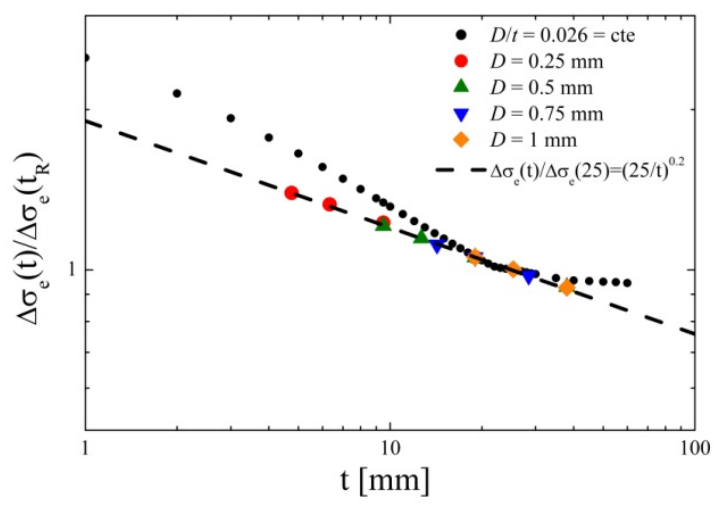

Figure 6: Normalised fatigue limit as a function of thickness, for $\mathrm{D} / \mathrm{t}=$ cte and $\mathrm{D}=0.25,0.5,0.75$ and $1 \mathrm{~mm} . \mathrm{t}_{\mathrm{R}}=25 \mathrm{~mm}$.

The aforementioned results verify that fatigue limit prediction in a $19 \mathrm{~mm}$ butt-weld with undercuts is a conservative approach for tolerance determination in industry, when thicknesses are below $19 \mathrm{~mm}$. For thicker plates, it is reasonable to apply a correction factor according to Eq. (4). An exponent $n=0.2$ and $t_{\mathrm{R}}=25$ is found to best fit behaviour of defective welds. In contrast, as-welded undercut-free joints may be better described by an exponent $n=0.25$ [25]. However, it must be highlighted that flawless welds are seldom found in real components, and it is therefore reasonable to adopt 0.2 in codes and regulations.

\subsection{Loading correction}

In order to further verify extension of previous results to a wider range of situation, loading mode was changed from four points bending to traction, and the resistance curve method was applied. This was done for a single undercut depth, $D=0.5 \mathrm{~mm}$, giving predictions displayed in the Frost diagram in Figure 7. Three different initial crack lengths were analysed, showing flattering of the curve with increasing crack size. According to obtained outcomes, fatigue limits of welded joints containing undercuts under traction are very similar to those resulting from bending.

The fact that the loading mode does not generate significant variation in the fatigue limit of defective butt welds supports previous discussion about tolerances in industry.

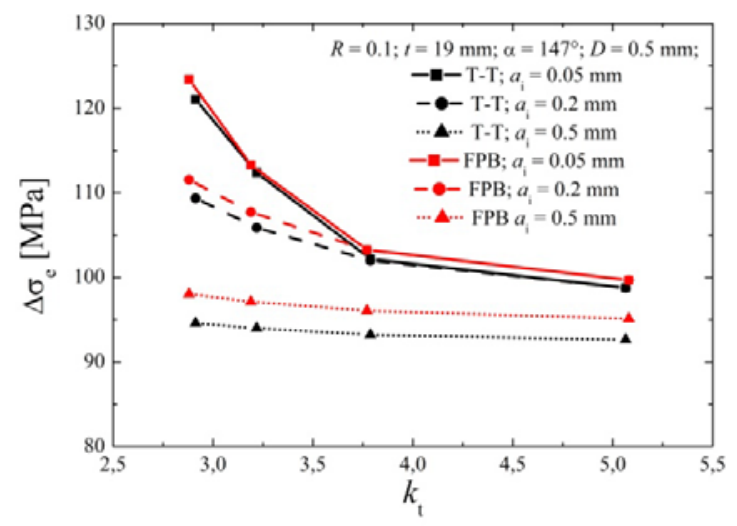

Figure 7: Frost diagram comparing fatigue limit of butt-weld with undercuts under traction (T-T) and bending (FPB).

\section{Conclusions}

A fracture mechanic approach that uses the resistance curve method was employed to predict fatigue limit of welded components containing undercuts. Methodology proved to be a useful tool to quantify the effect of different variables, like defect dimensions, overall weld geometry, load scheme and residual stresses, among others. Consequently, parametric studies can be developed to compare the importance of involved variables. Less meaningful variables can be simplified, focusing the attention to significant parameters.

Results were compared with tolerances adopted in current regulation for undercuts. It was demonstrated that undercut depth is the most important variable 
describing weld behaviour, and not undercut radius, width or length, as it is assumed in many studies.

It was shown that good correlation exists between predictions and FAT values considered in documents. A decrease in tolerances is seen when expected fatigue strength is higher. Trend is properly described by outcomes obtained, and the majority of standard tolerances lay between predictions for stress-relieved welds $(R=0.1)$ and those considering residual stresses. Real welds may experience stress relief during fatigue damage, and therefore, associated curve might be located at an intermediate level. Correlation of fatigue limit obtained from theoretical S-N curves and prediction was best satisfied by an undercut $1 \mathrm{~mm}$ deep, at $R=0.5$. However, S-N curves are known to be very conservative for long fatigue lives.

Methodology was also used to assess the effect of thickness, showing that predictions are safe for $t \leq 19$ $\mathrm{mm}$. However, for thicker welds, a correction/reduction factor should be accounted for, as mentioned in normative. Exponent $n=0.2$ best describes the trend for welds with undercuts, in accordance with literature.

Finally, the change of the loading mode from bending to traction does not seem to generate significant changes to predicted fatigue strength.

Authors express their gratitude to the funding provided by CONICET (Consejo Nacional de Investigaciones Científicas y Técnicas), and by Agencia Nacional de Promoción Científica Tecnológica, Argentina (PICT 2013 Nro.0110).

\section{References}

1. SS-EN ISO 5817. Welding. Fusion-welded joints in steel, nickel, titanium and their alloys. Quality levels for imperfections, ISO/TC 44/SC 10 (2014)

2. British Standard, BS 7910:2013+A1:2015 Guide to methods for assessing the acceptability of flaws in metallic structures, BSI Standards Limited (2013)

3. API Standard, 579-1/ASME FFS-1 2007, FitnessFor-Service, New York: ASME (2007)

4. British Energy Generation Limited, Assessment of the integrity of structures containing defects, R6 Revision 4, Amendment 7 (2009)

5. A.F. Hobbacher, Recommendations for Fatigue Design of Welded Joints and Components, $2^{\text {nd }}$ ed., Springer International Publishing (2016)

6. Det Norske Veritas, DNVGL-RP-C203. Fatigue design of offshore steel structures (2016)

7. C. Steimbreger, M.D. Chapetti, Int. J. Fatigue, 105, 296-304 (2017)

8. AWS, AWS D1.1/D1.1M:2015. Structural Welding code-Steel, American Welding Society (2015)

9. ASME, ASME BPVC - Section I, Rules for Construction of Power Boilers, American Society of Mechanical Engineers (2015).

10. ASME, ASME BPVC - Section III, Division 1, Subsection NF: Supports, American Society of Mechanical Engineers (2010).
11. ASME, ASTM BPVC - Section VIII, Division I, Rules for Construction of Pressure Vessels, American Society of Mechanical Engineers (2015).

12. British Standard, BS 7608-2014: Guide to fatigue design and assessment of steel products, BSI Standards Limited (2014)

13. British Standard, BS-EN ISO 15609-1:2004: Specification and qualification of welding procedures for metallic materials. BSI Standards Limited (2004)

14. H. Petershagen, Weld. World, 28(7/8), 114-125 (1990)

15. K. Iida, M. Sato, M. Nagai, Weld. World, 39(5): 262-271 (1997)

16. API, API 1104: Welding of Pipelines and Related Facilities , $21^{\text {st }}$ ed., API Publishing Services, Washington, DC (2013)

17. B. Jonsson, G. Dobmann, A.F. Hobbacher, M. Kassner, G. Marquis, IIW Guidelines on weld quality in relationship to fatigue strength, IIW Collection, Springer International Publishing, Switzerland (2016)

18. J.R. Spadea, K.H. Frank, Fatigue strength of filletwelded transverse stiffeners with undercuts, Research Report 0-4178-1: Fillet weld detailing for stiffener, Texas Department of Transportation (2004)

19. Volvo Group. STD 181-0004. Weld Quality Standard (2016)

20. T. Björk, J. Samuelsson, G.B. Marquis, Weld. World, 52(1/2): 34-46 (2008)

21. B. Jonsson, J. Samuelsson, G.B. Marquis, Weld. World, 55(11/12): 79-88 (2011)

22. W. Fricke, IIW Recommendations for the fatigue assessment of welded structures by notch stress analysis IIW-2006-09, Woodhead Publishing Limited, Cambridge, England (2012)

23. Det Norske Veritas, DNVGL-CG-0129. Class Guideline: Fatigue Assessment of Ship Structures (2015)

24. Dassault Systèmes, Simulia. Abaqus 6.13 User manual, Providence, RI, USA (2013)

25. M.D. Chapetti, J. Belmonte, T. Tagawa, T. Miyata, Sci. Tech. Weld. Join. 9(5), 430-438 (2004)

26. M.D. Chapetti, Int. J. Fatigue, 25(12), 1319-26 (2003)

27. T.R. Gurney, Fatigue of welded structures, $2^{\text {nd }}$ ed., London: Cambridge UP (1979)

28. S.J. Maddox, Fatigue strength of welded structures, $2^{\text {nd }}$ ed., Abington, Cambridge (1991)

29. S. Berge, Eng. Frac. Mechs., 21(2), 423-435 (1985)

30. A.M. Al-Mukhtar, J. Fail. Anal. Preven., 13, 63-71 (2013)

31. I. Lotsberg, Int. J. Fatigue, 66, 86-100 (2014) 